Letter

\title{
Inductive Power Transfer Systems for Bus-Stop-Powered Electric Vehicles
}

\author{
Chung-Chuan Hou * and Kuei-Yuan Chang \\ Department of Electrical Engineering, Chung Hua University, Hsinchu 30012, Taiwan; f26714317@gmail.com \\ * Correspondence: bird@chu.edu.tw; Tel.: +886-3-518-6351 \\ Academic Editor: Chunhua Liu \\ Received: 20 February 2016; Accepted: 20 June 2016; Published: 30 June 2016
}

\begin{abstract}
This study presents an inductive power transfer (IPT) system for electric vehicles (EVs) based on EE-shaped ferrite cores. The issues of the IPT system such as efficiency, air gap, displacement, dislocation, and motion are discussed. Furthermore, finite element analysis software is utilized to simulate the IPT system operated under large air gap conditions. Simulation and measurement results are presented to validate the performance of the proposed scheme and meet the requirements for bus-stop-powered EVs.
\end{abstract}

Keywords: inductive power transfer; bus-stop-powered; electric vehicles

\section{Introduction}

As the air pollution problems caused by gasoline-powered vehicles have become more and more serious, electric vehicles (EVs) [1-3] or hybrid EVs have been regarded as good solutions and gained increasing attention. However, the batteries used in EVs or hybrid EVs have some significant disadvantages, such as high cost and heaviness, limited capacitance and charging/discharging cycles, and long charging time, etc. The roadway-powered EVs [4-8] scheme has therefore been discussed to reduce the battery capacitance and to extend the driving range. This study would like to furthermore present the inductive power transfer (IPT) system [9-13] for bus-stop-powered EVs [14] with much less cost than the roadway-powered EVs system.

Figure 1 shows the IPT system for bus-stop-powered EVs or hybrid EVs. The active front-end (AFE) converter is utilized as interface between the AC voltage grid and DC voltage grid. The advantages of the AFE converter are bidirectional power flow and low total harmonic distortion (THD) of the line current. The primary side of the IPT system is DC-AC H-bridge inverters. The multi-H-bridge inverters are utilized to increase the transfer power and efficiency of the IPT system. The secondary side of the IPT system is a pick-up coil and receiver built in the EVs or hybrid EVs. The IPT receiver is utilized to charge up battery or supply power to motor through the inverter. The IPT system for moving EVs or hybrid EVs is convenient for charging up battery and could also extend driving range. Furthermore, the position regulation sensors of the IPT system are utilized to control the operation of multi-H-bridge inverters and improve the efficiency of the IPT system. 


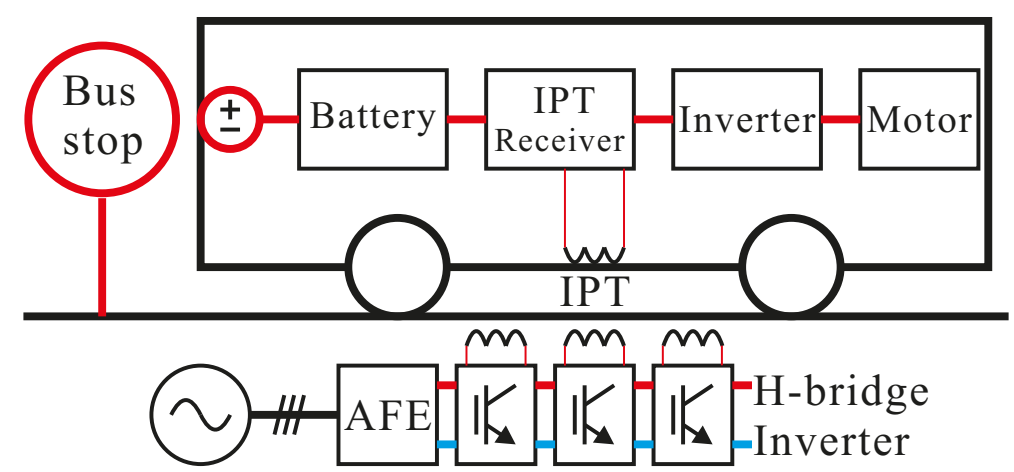

Figure 1. Inductive power transfer system for bus-stop-powered EVs or hybrid EVs.

\section{Inductive Power Transfer System}

Figure 2 shows the simplified IPT system based on EE-shaped ferrite cores for bus-stop-powered EVs or hybrid EVs. As shown in Figure $2 a$, the DC bus voltage is $V_{d c}$, the DC-AC H-bridge inverter is utilized to generate the high frequency square wave voltage $V_{i n}$. The EE-shaped ferrite cores are utilized to transfer the power to secondary side load (by pick-up coil and receiver). The primary inductance and secondary inductance are $L_{p}$ and $L_{s}$. The mutual inductance is $M\left(=L_{m}\right)$. The coupling coefficient $(k)$ is defined as in (1):

$$
k=\frac{M}{\sqrt{L_{P} L_{S}}}
$$

As shown in Figure 2b, the dimensions of the EE-shaped cores are A $(80 \mathrm{~mm}), \mathrm{B}(38 \mathrm{~mm})$, $\mathrm{C}(20 \mathrm{~mm}), \mathrm{D}(28 \mathrm{~mm}), \mathrm{E}(59 \mathrm{~mm}), \mathrm{F}(20 \mathrm{~mm}), \mathrm{G}(\mathrm{F} / 2), \mathrm{H}(\mathrm{E} / 2-\mathrm{F} / 2)$, and I (A/4-E/4). The material of the EE-shaped cores is 3C90 made by Ferroxcube (New Taipei City, Taiwan, R.O.C.). The relative permeability is 2300 (permeability of free space: $4 \pi \times 10^{-7} \mathrm{H} / \mathrm{m}$ ). Figure $2 \mathrm{c}$ shows the equivalent circuit of the primary series resonant and secondary parallel resonant (SP) topology IPT system and Figure $2 \mathrm{~d}$ shows the secondary parallel resonant $(\mathrm{P})$ topology IPT system, respectively.

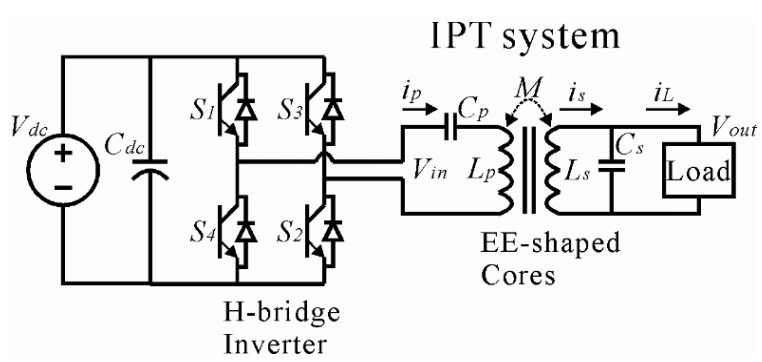

(a)

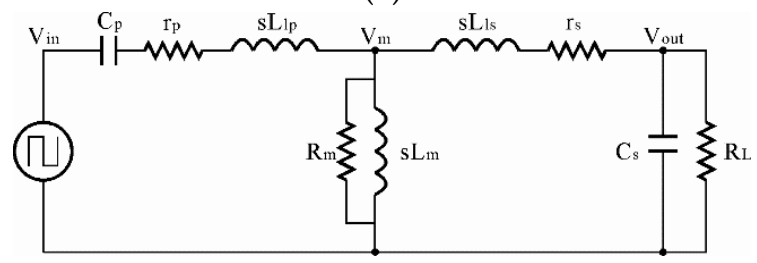

(c)

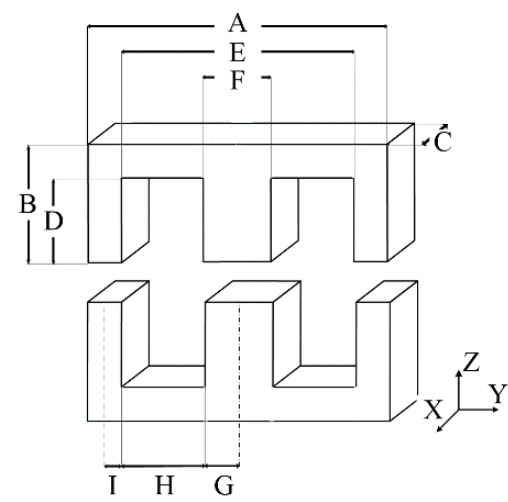

(b)

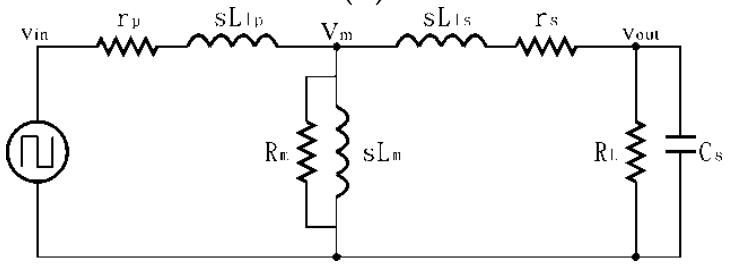

(d)

Figure 2. Simplified inductive power transfer system. (a) Circuit of the IPT system; (b) EE-shaped cores; (c) Equivalent circuit of the SP topology; (d) Equivalent circuit of the P topology. 
The mutual inductance is $M\left(=L_{m}\right)$ and the equivalent resistance of core loss is $R_{m}$. The primary and secondary leakage inductances are $L_{l p}$ and $L_{l s}$ as in (2).

$$
L_{l p}=(1-\mathbf{k}) L_{p}, L_{l s}=(1-\mathbf{k}) L_{s}
$$

The primary and secondary resistances are $r_{p}$ and $r_{s}$. The load is simplified as $R_{L}$. The primary series resonant capacitor is $C_{P}$ and the secondary parallel resonant capacitor is $C s$. The transfer function of the SP topology IPT system is given as in (3):

$$
\frac{v_{\text {out }}(s)}{v_{\text {in }}(s)}=\frac{s^{2} \times C_{P} \times L_{m} \times R_{L} /\left[R_{m} \times\left(R_{L}+r_{S}\right)\right]}{\left(1+\frac{s}{p_{H}}\right) \times\left(1+\frac{2 \zeta_{1}}{\omega_{n 1}} s+\frac{s^{2}}{\omega_{n 1}^{2}}\right) \times\left(1+\frac{2 \zeta_{2}}{\omega_{n 2}} s+\frac{s^{2}}{\omega_{n 2}^{2}}\right)}
$$

The pole $\left(\mathrm{s}=-P_{H}\right)$ operated at the high frequency domain is as in (4):

$$
p_{H}=R_{m} \times\left(\frac{1}{L_{l p}}+\frac{1}{L_{l s}}+\frac{1}{L_{m}}\right)
$$

The complex-conjugate poles operated at the low frequency domain are as in (5):

$$
s=-\left(\zeta_{1} \pm j \sqrt{1-\zeta_{1}^{2}}\right) \omega_{n 1}
$$

where the damping ratio is $\zeta_{1}=r_{P} C_{P} \omega_{n 1} / 2$, natural undamped frequency is $\omega_{n 1}=\sqrt{1 / C_{P}\left(L_{l p}+L_{m}\right)}$ and resonant frequency is $\omega_{r 1}=\sqrt{1-\zeta_{1}^{2}} \omega_{n 1}$, respectively.

The complex-conjugate poles operated at the middle frequency domain are as in (6):

$$
s=-\left(\zeta_{2} \pm j \sqrt{1-\zeta_{2}^{2}}\right) \omega_{n 2}
$$

where the damping ratio is $\zeta_{2}=1 / 2 R_{L} C_{S} \omega_{n 2}$, natural undamped frequency is $\omega_{n 2}=\sqrt{\frac{\left(1+r_{S} / R_{L}\right)}{C_{S}\left(L_{l s}+\frac{L_{l p} \times L_{m}}{L_{l p}+L_{m}}\right)}}$ and resonant frequency is $\omega_{r 2}=\sqrt{1-\zeta_{2}^{2}} \omega_{n 2}$, respectively.

According to (3), the transfer function of the IPT system with P topology is reduced as in (7):

$$
\frac{v_{\text {out }}(s)}{v_{\text {in }}(s)}=\frac{s \times L_{m} \times R_{L} /\left(r_{P} \times\left(R_{L}+r_{S}\right)\right)}{\left(1+\frac{s}{p_{L}}\right) \times\left(1+\frac{s}{p_{H}}\right) \times\left(1+\frac{2 \zeta_{2}}{\omega_{n 2}} s+\frac{s^{2}}{\omega_{n 2}^{2}}\right)}
$$

The high frequency pole $\left(\mathrm{s}=-P_{H}\right)$ is as in (4) and the low frequency pole $\left(\mathrm{s}=-P_{L}\right)$ is as in (8):

$$
p_{L}=r_{P} /\left(L_{l p}+L_{m}\right)
$$

The complex-conjugate poles operated at the middle frequency domain are as in (9):

$$
s=-\left(\zeta \pm j \sqrt{1-\zeta^{2}}\right) \omega_{n}
$$

where the damping ratio is $\zeta=1 / 2 R_{L} C_{S} \omega_{n}$, natural undamped frequency is $\omega_{n}=\sqrt{\frac{\left(1+r_{S} / R_{L}\right)}{C_{S}\left(L_{l s}+\frac{L_{p} \times L_{m}}{L_{l p}+L_{m}}\right)}}$ and resonant frequency is $\omega_{r}=\sqrt{1-\zeta^{2}} \omega_{n}$, respectively.

According to (3) and (7), there are two pairs of resonant poles in the SP topology IPT system and one pair of resonant poles in the P topology IPT system. 


\section{Frequency Response of the IPT System}

The parameters of the IPT system are as follows: the primary inductance and secondary inductance are $L p(325 \mu \mathrm{H})$ and $L s(325 \mu \mathrm{H})$. The primary series resonant capacitor is $C_{P}(0.2 \mu \mathrm{F})$ and the secondary parallel resonant capacitor is $C_{s}(0.2 \mu \mathrm{F})$. The resistances $r_{p}$ and $r_{s}$ are $0.72 \Omega$. The load resistance $R_{L}$ is $100 \Omega$.

Figure 3 shows the frequency response of the IPT system based on EE-shaped cores with varied air gap (fsw: 10-100 kHz). In SP topology, the resonant frequencies $\omega_{\mathrm{r} 1}$ and $\omega_{\mathrm{r} 2}$ move to each other as the air gap is increased as shown in Figure 3a. In P topology, the resonant peak value is decreased as the air gap is increased as shown in Figure 3b. Therefore, the SP topology is suitable for a large air gap IPT system and the P topology suits a small air gap IPT system. The coupling coefficient and resonant frequency of the IPT system with varied air gap are given in Table 1.

Table 1. Coupling coefficient and resonant frequency of the IPT system with varied air gap.

\begin{tabular}{cccc}
\hline Gap & $\mathbf{5 ~} \mathbf{~ m m}$ & $\mathbf{1 0 ~} \mathbf{~ m}$ & $\mathbf{2 0} \mathbf{~ m m}$ \\
\hline$L_{l p}$ & $217.7 \mu \mathrm{H}$ & $237.2 \mu \mathrm{H}$ & $282.7 \mu \mathrm{H}$ \\
$L_{l s}$ & $217.7 \mu \mathrm{H}$ & $237.2 \mu \mathrm{H}$ & $282.7 \mu \mathrm{H}$ \\
$L_{m}$ & $107.3 \mu \mathrm{H}$ & $87.8 \mu \mathrm{H}$ & $42.3 \mu \mathrm{H}$ \\
$k$ & 0.33 & 0.27 & 0.13 \\
$\omega_{\mathrm{r} 1}$ & $15 \mathrm{kHz}$ & $17 \mathrm{kHz}$ & $20 \mathrm{kHz}$ \\
$\omega_{\mathrm{r} 2}$ & $23 \mathrm{kHz}$ & $22 \mathrm{kHz}$ & $20 \mathrm{kHz}$ \\
$\omega_{\mathrm{r}}$ & $20 \mathrm{kHz}$ & $20 \mathrm{kHz}$ & $20 \mathrm{kHz}$ \\
\hline
\end{tabular}

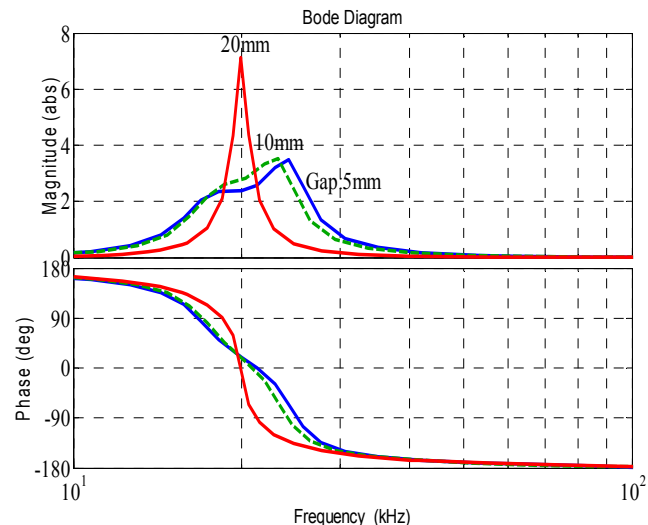

(a)

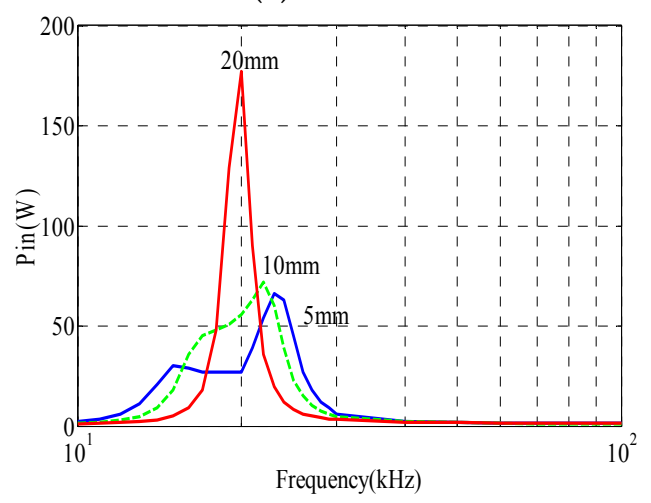

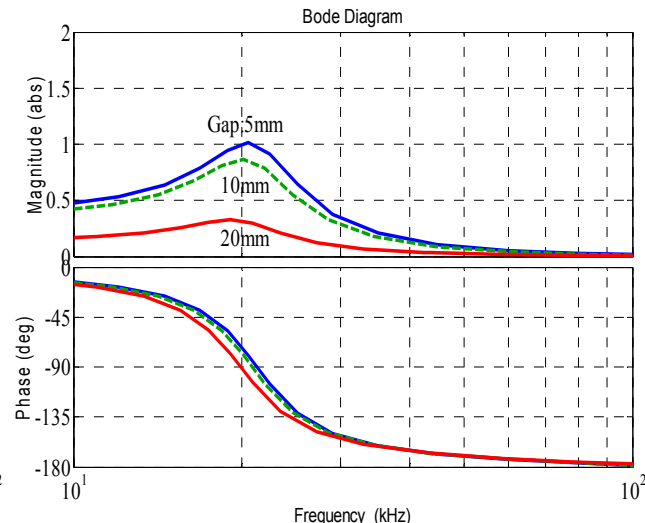

(b)

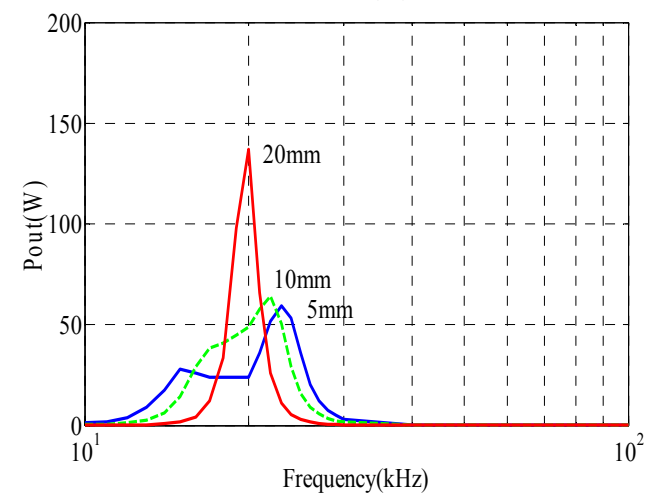

(c)

Figure 3. Cont. 

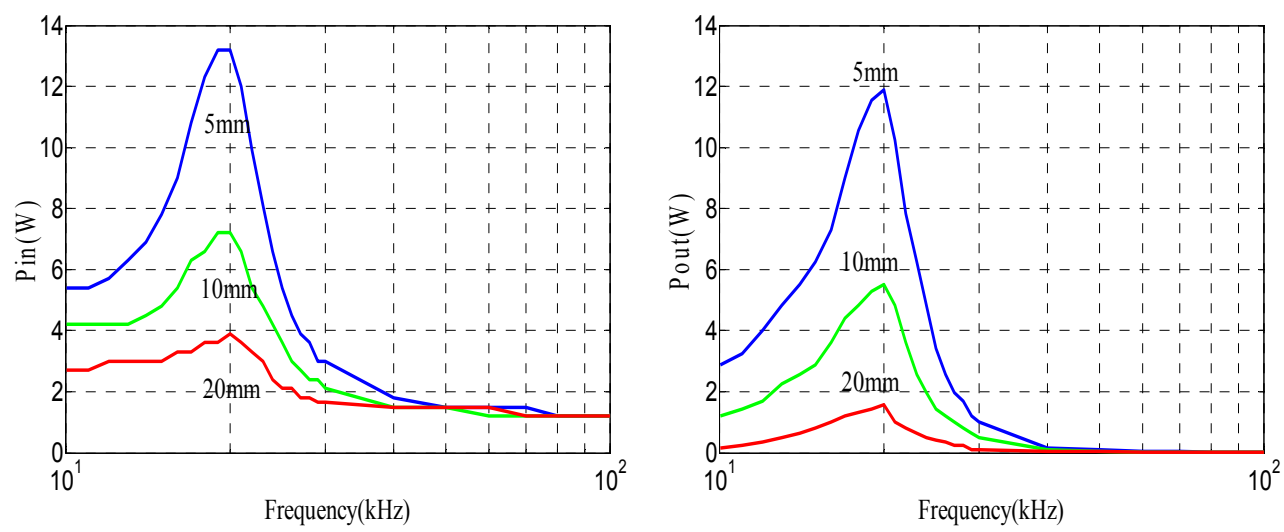

(d)

Figure 3. Frequency response of the IPT system based on EE-shaped cores with varied air gap. (a) SP topology (MATLAB); (b) P topology (MATLAB); (c) Input power and output power of SP topology (test results; $\mathrm{V}_{\mathrm{dc}}: 30 \mathrm{~V}$ ); (d) Input power and output power of $\mathrm{P}$ topology (test results; $\mathrm{V}_{\mathrm{dc}}: 30 \mathrm{~V}$ ).

Figure $3 \mathrm{c}$ shows the input power and output power of the SP topology IPT system with varied air gap (test results; $\left.\mathrm{V}_{\mathrm{dc}}: 30 \mathrm{~V}\right)$. The resonant frequencies of the IPT system are $15 \mathrm{kHz}\left(\omega_{\mathrm{r} 1}\right)$ and $23 \mathrm{kHz}$ $\left(\omega_{\mathrm{r} 2}\right)$ under air gap $5 \mathrm{~mm}, 17 \mathrm{kHz}\left(\omega_{\mathrm{r} 1}\right)$ and $22 \mathrm{kHz}\left(\omega_{\mathrm{r} 2}\right)$ under air gap $10 \mathrm{~mm}$, and $20 \mathrm{kHz}\left(\omega_{\mathrm{r} 1,2}\right)$ under air gap $20 \mathrm{~mm}$, respectively. The input power and output power are increased and the efficiency is decreased as air gap increased. The measurement results of the SP topology IPT system are given in Table 2. Figure $3 \mathrm{~d}$ shows the input power and output power of the P topology IPT system with varied air gap (test results; $\mathrm{V}_{\mathrm{dc}}: 30 \mathrm{~V}$ ). The input power, output power, and the efficiency are decreased as air gap increased. The measurement results of the P topology IPT system are given in Table 2. As shown in Figure 3, the measurement results agree with the simulation results produced by using MATLAB.

Table 2. Input power, output power, and efficiency of the IPT system.

\begin{tabular}{|c|c|c|c|c|c|c|}
\hline \multirow{4}{*}{$\begin{array}{c}\text { SP } \\
\text { TOPOLOGY }\end{array}$} & Gap & $\begin{array}{c}5 \mathrm{~mm} \omega_{\mathrm{r} 1}: \\
15 \mathrm{kHz}\end{array}$ & $\begin{array}{c}5 \mathrm{~mm} \omega_{\mathrm{r} 2}: \\
23 \mathrm{kHz}\end{array}$ & $\begin{array}{c}10 \mathrm{~mm} \omega_{\mathrm{r} 1}: \\
17 \mathrm{kHz}\end{array}$ & $\begin{array}{c}10 \mathrm{~mm} \omega_{\mathrm{r} 2}: \\
22 \mathrm{kHz}\end{array}$ & $\begin{array}{c}20 \mathrm{~mm} \omega_{\mathrm{r} 1,2}: \\
20 \mathrm{kHz}\end{array}$ \\
\hline & Input power & $30 \mathrm{~W}$ & $66 \mathrm{~W}$ & $45 \mathrm{~W}$ & $72 \mathrm{~W}$ & $177 \mathrm{~W}$ \\
\hline & Output power & $28 \mathrm{~W}$ & $59.3 \mathrm{~W}$ & $38.4 \mathrm{~W}$ & $64 \mathrm{~W}$ & $136.9 \mathrm{~W}$ \\
\hline & Efficiency & $94 \%$ & $90 \%$ & $85 \%$ & $89 \%$ & $77 \%$ \\
\hline \multirow{4}{*}{ P TOPOLOGY } & Gap & \multicolumn{2}{|c|}{$5 \mathrm{~mm} \omega_{\mathrm{r}}: 20 \mathrm{kHz}$} & \multicolumn{2}{|c|}{$10 \mathrm{~mm} \omega_{\mathrm{r}}: 20 \mathrm{kHz}$} & $\begin{array}{c}20 \mathrm{~mm} \omega_{\mathrm{r}}: \\
20 \mathrm{kHz}\end{array}$ \\
\hline & Input power & \multicolumn{2}{|c|}{$13.2 \mathrm{~W}$} & \multicolumn{2}{|c|}{$7.2 \mathrm{~W}$} & $3.9 \mathrm{~W}$ \\
\hline & Output power & \multicolumn{2}{|c|}{$11.9 \mathrm{~W}$} & \multicolumn{2}{|c|}{$5.5 \mathrm{~W}$} & $1.6 \mathrm{~W}$ \\
\hline & Efficiency & \multicolumn{2}{|c|}{$90 \%$} & \multicolumn{2}{|c|}{$77 \%$} & $40 \%$ \\
\hline
\end{tabular}

\section{Simulation and Experimental Results}

Figure 4 shows the prototype of measurement for the P topology IPT system operated at small air gap. The multi-H-bridge inverters are utilized to increase the transfer power and efficiency of the $\mathrm{P}$ topology IPT system as shown in Figure 4a. The X-Z table and controller are utilized to move the pick-up coil and IPT receiver along the $X$-axis as shown in Figure $4 \mathrm{~b}$. The parameters of measurement are the same as Section 3. The issues of the IPT system [13] such as efficiency, air gap (Z-axis), displacement (X-axis), dislocation ( $Y$-axis), and motion ( $X$-axis) are discussed as follow: 


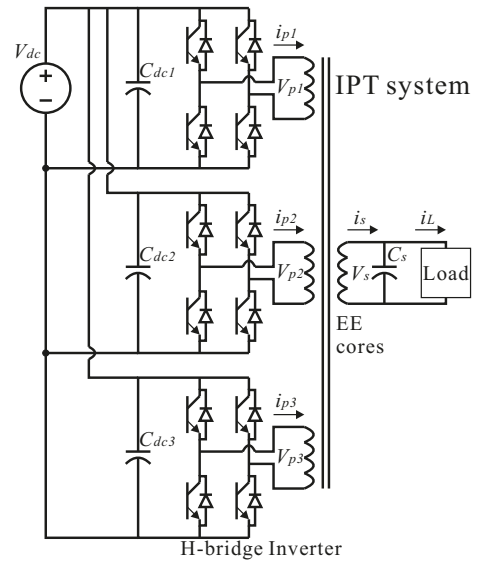

(a)

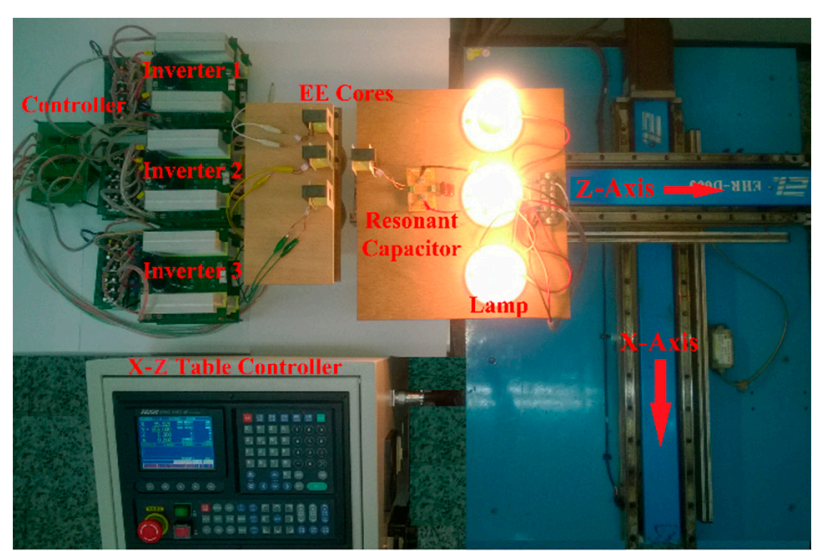

(b)

Figure 4. Prototype of measurement for the P topology IPT system. (a) multi-H-bridge inverters (b) prototype of measurement.

\subsection{Air Gap}

Figure 5 shows the efficiency, input power, and output power of the P topology IPT system based on one H-bridge inverter with varied air gap and operating frequency. The switching frequency (fsw) is from $10 \mathrm{kHz}$ to $100 \mathrm{kHz}$. As shown in Figure 5a, for various operating frequencies, the IPT system exhibits superior performance at the resonant frequency $(20 \mathrm{kHz})$. The efficiency of the IPT system is decreased by increased operating frequency. Table 3 shows the efficiency, input power, and output power of the P topology IPT system at $20 \mathrm{kHz}$. The maximum efficiency of the IPT system is $93 \%$ at air gap $5 \mathrm{~mm}$. Figure $5 \mathrm{~b}$ shows the efficiency, input power, and output power of the IPT system with varied air gap from $5 \mathrm{~mm}$ to $65 \mathrm{~mm}$ (fsw: $20 \mathrm{kHz}$ ). The efficiency, input power, output power, and power loss of the IPT system are $50.9 \%, 49.5 \mathrm{~W}, 25.2 \mathrm{~W}$, and $24.3 \mathrm{~W}$ (gap: $21 \mathrm{~mm}$ ). The performances of the $P$ topology IPT system are increased by a decreased air gap.

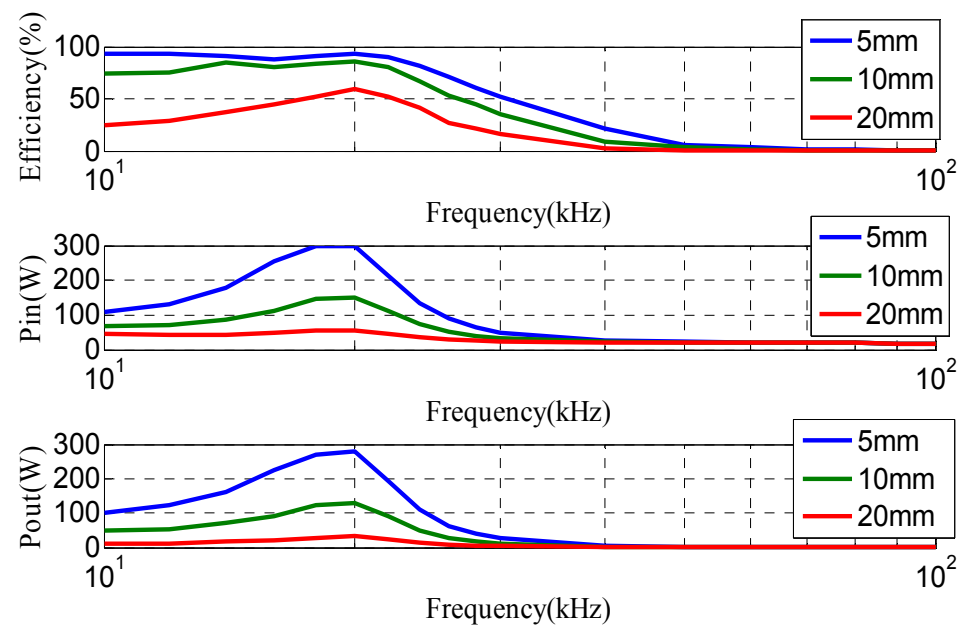

(a)

Figure 5. Cont. 

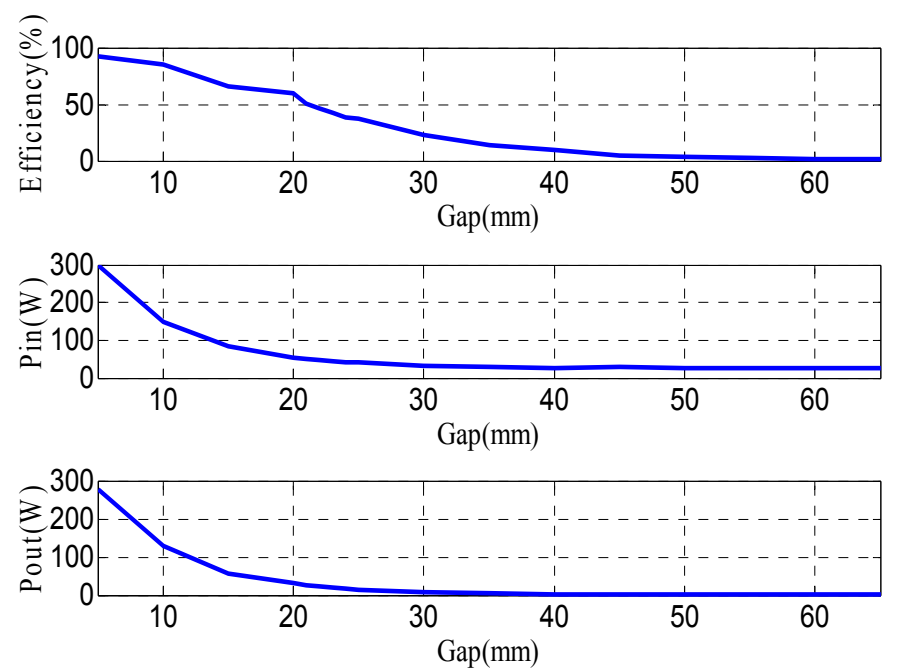

(b)

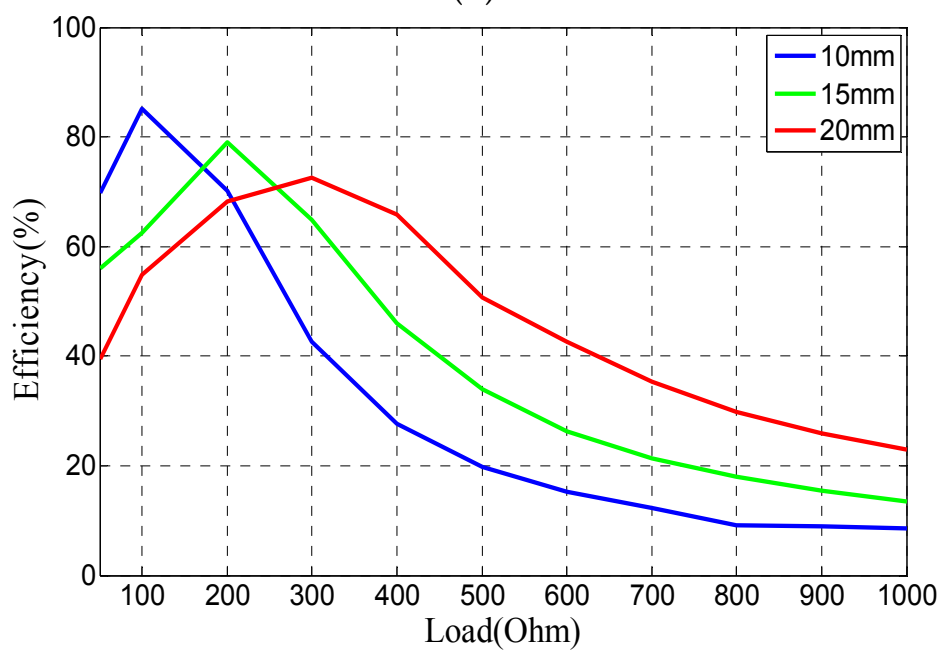

(c)

Figure 5. Efficiency, input power, and output power of the P topology IPT system with varied air gap and frequency $\left(\mathrm{V}_{\mathrm{dc}}: 150 \mathrm{~V} ; \mathrm{R}_{\mathrm{L}}: 100 \Omega\right.$ ). (a) Efficiency, input power, and output power; (b) Varied air gap from $5 \mathrm{~mm}$ to $65 \mathrm{~mm}(20 \mathrm{kHz})$; (c) Varied load $(20 \mathrm{kHz})$.

Table 3. Efficiency, input power, and output power of the IPT system with varied air gap at $20 \mathrm{kHz}$.

\begin{tabular}{cccc}
\hline Air Gap (mm) & $\mathbf{5}$ & $\mathbf{1 0}$ & $\mathbf{2 0}$ \\
\hline Efficiency & $93 \%$ & $85 \%$ & $60 \%$ \\
Input Power(W) & 300 & 150 & 54 \\
Output Power(W) & 278 & 128 & 32 \\
\hline
\end{tabular}

Figure $5 \mathrm{c}$ shows the efficiency of the $\mathrm{P}$ topology IPT system with varied load $50-1000 \Omega\left(\mathrm{V}_{\mathrm{dc}}: 150 \mathrm{~V}\right.$; fsw: $20 \mathrm{kHz}$ ). The efficiency, input power, and output power of the P topology IPT system are $85 \%$, $150 \mathrm{~W}$, and $128 \mathrm{~W}$ under load $100 \Omega$ (gap: $10 \mathrm{~mm}$ ). The efficiency, input power, and output power of the P topology IPT system are $79 \%, 150 \mathrm{~W}$, and $119 \mathrm{~W}$ under load $200 \Omega$ (gap: $15 \mathrm{~mm}$ ). The efficiency, input power, and output power of the P topology IPT system are $72 \%, 120 \mathrm{~W}$, and $86 \mathrm{~W}$ under load $300 \Omega$ (gap: $20 \mathrm{~mm}$ ). The efficiency of the P topology IPT system is affected by the load and air gap. 


\subsection{Displacement}

The displacement is defined as moving along the $X$-axis. Figure 6 shows the displacement effect of the IPT system based on one H-bridge inverter with varied air gap from $5 \mathrm{~mm}$ to $40 \mathrm{~mm}$ (fsw: $20 \mathrm{kHz}$ ). Table 4 shows the efficiency, input power, output power, and power loss of the IPT system. Table 4 is for displacements of $10 \mathrm{~mm}$ and $20 \mathrm{~mm}$, respectively. The performances of the IPT system are increased by decreased displacement.
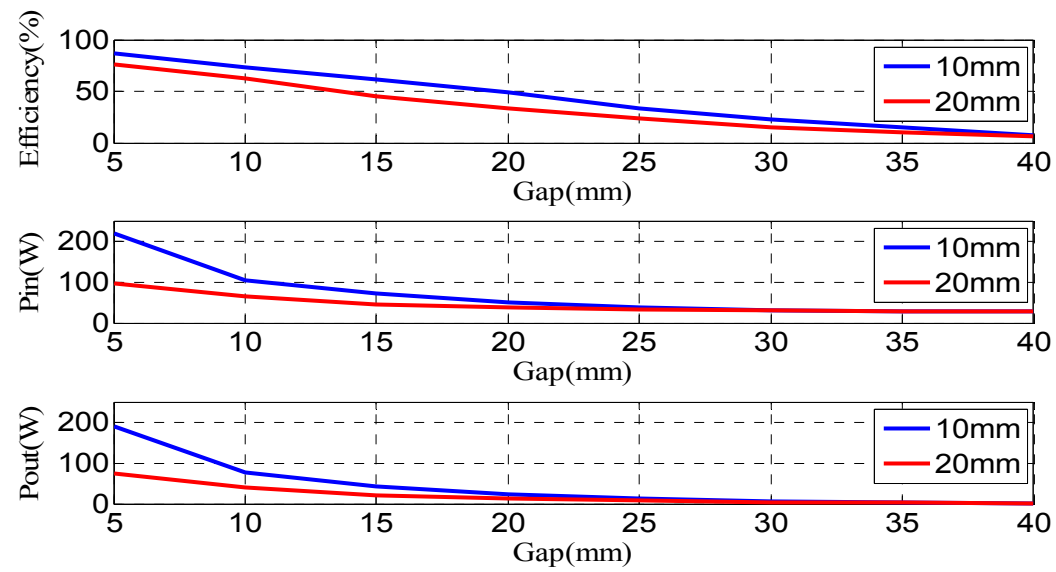

(a)

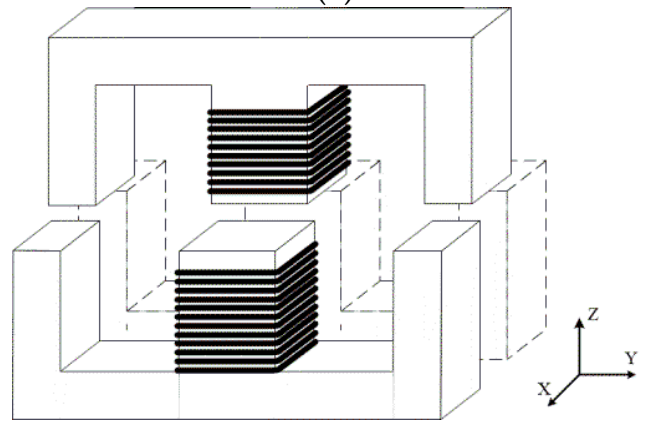

(b)

Figure 6. Displacement effect of the IPT system with varied air gap from $5 \mathrm{~mm}$ to $40 \mathrm{~mm}\left(\mathrm{~V}_{\mathrm{dc}}: 150 \mathrm{~V}\right.$; fsw: $20 \mathrm{kHz}$ ). (a) Efficiency, input power; and output power (b) Displacement.

Table 4. Displacement effect of the IPT system with varied air gap from $5 \mathrm{~mm}$ to $40 \mathrm{~mm}$ (fsw: $20 \mathrm{kHz}$ ).

\begin{tabular}{|c|c|c|c|c|c|c|c|c|c|}
\hline Displacement & Air Gap (mm) & 5 & 10 & 15 & 20 & 25 & 30 & 35 & 40 \\
\hline \multirow{3}{*}{$\begin{array}{l}\text { Displacement: } \\
10 \mathrm{~mm}\end{array}$} & Efficiency & $86.8 \%$ & $73.2 \%$ & $61.4 \%$ & $49.5 \%$ & $33.3 \%$ & $22.9 \%$ & $14.8 \%$ & $7.4 \%$ \\
\hline & Input power $(\mathrm{W})$ & 219 & 105 & 72 & 49.5 & 37.5 & 31.5 & 28.5 & 27 \\
\hline & Output power (W) & 191.1 & 77.2 & 44.1 & 24.5 & 12.5 & 7.2 & 4.2 & 2 \\
\hline \multirow{3}{*}{$\begin{array}{l}\text { Displacement: } \\
20 \mathrm{~mm}\end{array}$} & Efficiency & $76.3 \%$ & $62.7 \%$ & $45.4 \%$ & $33.3 \%$ & $24.2 \%$ & $15.0 \%$ & $10.6 \%$ & $6.0 \%$ \\
\hline & Input power $(\mathrm{W})$ & 97.5 & 64.5 & 46.5 & 37.5 & 33 & 30 & 27 & 27 \\
\hline & Output power (W) & 74.4 & 40.5 & 21.1 & 12.5 & 8 & 4.5 & 2.9 & 1.6 \\
\hline
\end{tabular}

\subsection{Dislocation}

The dislocation is defined as moving along the $Y$-axis. Figure 7 shows the dislocation effect of the IPT system based on one H-bridge inverter with varied air gap from $5 \mathrm{~mm}$ to $40 \mathrm{~mm}$ (fsw: $20 \mathrm{kHz}$ ). The dislocation effect of the IPT system with varied air gap is given in Table 5. Table 5 is for dislocations of $10 \mathrm{~mm}$ and $20 \mathrm{~mm}$, respectively. The performances of the IPT system are increased by decreased dislocation. 

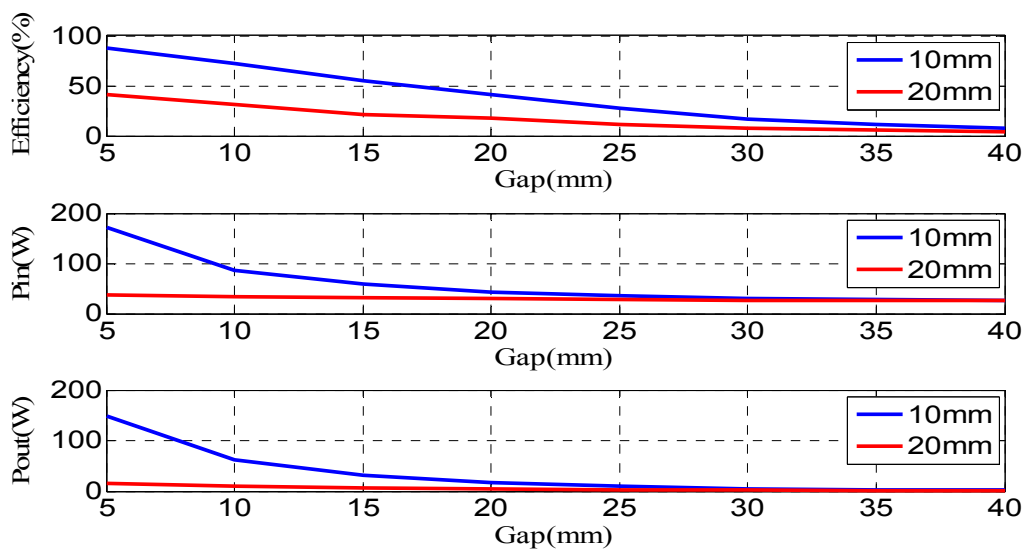

(a)

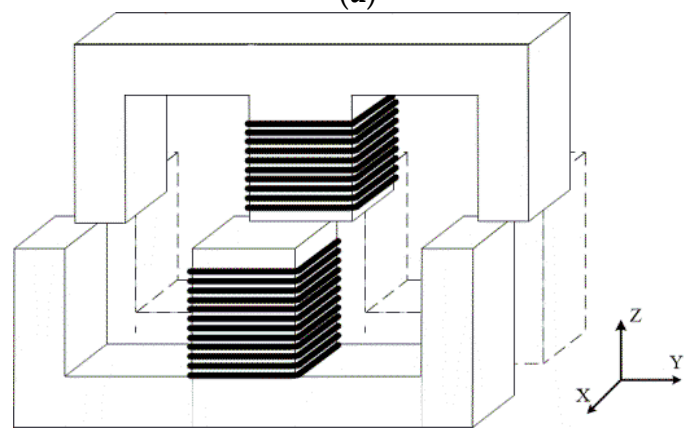

(b)

Figure 7. Dislocation effect of the IPT system with varied air gap from $5 \mathrm{~mm}$ to $40 \mathrm{~mm}$ (fsw: $20 \mathrm{kHz}$ ). (a) Efficiency, input power; and output power (b) Dislocation.

Table 5. Dislocation effect of the IPT system with varied air gap from $5 \mathrm{~mm}$ to $40 \mathrm{~mm}$.

\begin{tabular}{llllllllll}
\hline Dislocation & Air Gap (mm) & $\mathbf{5}$ & $\mathbf{1 0}$ & $\mathbf{1 5}$ & $\mathbf{2 0}$ & $\mathbf{2 5}$ & $\mathbf{3 0}$ & $\mathbf{3 5}$ & $\mathbf{4 0}$ \\
\hline \multirow{2}{*}{ Dislocation: } & Efficiency & $87.5 \%$ & $72.1 \%$ & $54.7 \%$ & $41.4 \%$ & $28.1 \%$ & $17.1 \%$ & $11 \%$ & $7.4 \%$ \\
$\mathbf{1 0} \mathbf{~ m m}$ & Input power (W) & 171 & 87 & 58.5 & 43.3 & 36 & 30 & 28.5 & 27 \\
& Output power (W) & 147.9 & 62.7 & 32 & 18 & 10.1 & 5.1 & 3.1 & 2 \\
\hline \multirow{2}{*}{ Dislocation: } & Efficiency & $41.8 \%$ & $31.2 \%$ & $21.7 \%$ & $18.1 \%$ & $11.8 \%$ & $8.1 \%$ & $6.0 \%$ & $4.4 \%$ \\
$\mathbf{2 0} \mathbf{~ m m}$ & Input power (W) & 37.5 & 34.5 & 31.5 & 30 & 28.5 & 27 & 27 & 25.5 \\
& Output power (W) & 15.7 & 10.8 & 6.8 & 5.4 & 3.3 & 2.2 & 1.6 & 1.1 \\
\hline
\end{tabular}

\subsection{Motion}

As shown in Figure 4, three H-bridge inverters are connected with each primary E-shaped core and are utilized to transfer power to a secondary E-shaped core. The width of E-shaped core is $C=20 \mathrm{~mm}$ (Figure $2 \mathrm{~b}$ ). The space of each primary E-shaped core is $20 \mathrm{~mm}$ (Table 4). The three operation modes of three $\mathrm{H}$-bridge inverters are controlled by position regulation sensors. The mode $1 \mathrm{H}$ is designed as one $\mathrm{H}$-bridge inverter operated each time; mode $2 \mathrm{H}$, two $\mathrm{H}$-bridge inverters; mode $3 \mathrm{H}$, three $\mathrm{H}$-bridge inverters, respectively. The operating range of mode $1 \mathrm{H}$ for each $\mathrm{H}$-bridge inverter is $40 \mathrm{~mm}$ without overlap as moving along $\mathrm{X}$-axis. The total operating range of mode $1 \mathrm{H}$ for three $\mathrm{H}$-bridge inverters is $120 \mathrm{~mm}$. The operating range of mode $2 \mathrm{H}$ for each $\mathrm{H}$-bridge inverter is $80 \mathrm{~mm}$ as moving along $\mathrm{X}$-axis. The nearby two H-bridge inverters are operated with $40 \mathrm{~mm}$ overlap. The total operating range of mode $2 \mathrm{H}$ for three $\mathrm{H}$-bridge inverters is $160 \mathrm{~mm}$. The operating range of mode $3 \mathrm{H}$ for three $\mathrm{H}$-bridge inverters are the same range $140 \mathrm{~mm}$ as moving along the $\mathrm{X}$-axis.

Figure 8 shows the efficiency, input power, and output power of the IPT system in motion. The air gaps of the IPT system are $10 \mathrm{~mm}$ (Figure $8 \mathrm{a}$ ) and $20 \mathrm{~mm}$ (Figure $8 \mathrm{~b}$ ) as moving along the $X$-axis. As shown in Figure $8 \mathrm{a}, \mathrm{b}$, comparing modes $1 \mathrm{H}, 2 \mathrm{H}$, and $3 \mathrm{H}$, the efficiency, input power, and output power of mode $1 \mathrm{H}$ vary seriously due to each $\mathrm{H}$-bridge inverter being operated without overlap; the 
input power of mode $3 \mathrm{H}$ is high, but the efficiency of mode $3 \mathrm{H}$ is low due to the wide operating range for three $\mathrm{H}$-bridge inverters; the efficiency, input power, and output power of mode $2 \mathrm{H}$ are high and stable due to the adequate overlap operation for three H-bridge inverters. The motion effect of the IPT system as moving along $\mathrm{X}$-axis is given in Table 6 (mode $1 \mathrm{H}$ ), Table 7 (mode $2 \mathrm{H}$ ), and Table 8 (mode $3 \mathrm{H}$ ), respectively. The efficiency, input power, and output power of mode $2 \mathrm{H}$ are $76 \%, 224 \mathrm{~W}$, and $169 \mathrm{~W}$ (air gap: $10 \mathrm{~mm}$; $X$-axis: $0 \mathrm{~mm}$ ) and 51\%, $107 \mathrm{~W}$, and $54.1 \mathrm{~W}$ (air gap: $20 \mathrm{~mm}$; $X$-axis: $0 \mathrm{~mm}$ ). Among mode $1 \mathrm{H}, 2 \mathrm{H}$, and $3 \mathrm{H}$, mode $2 \mathrm{H}$ exhibits superior performances of the IPT system and meets the requirements for bus-stop-powered EVs.
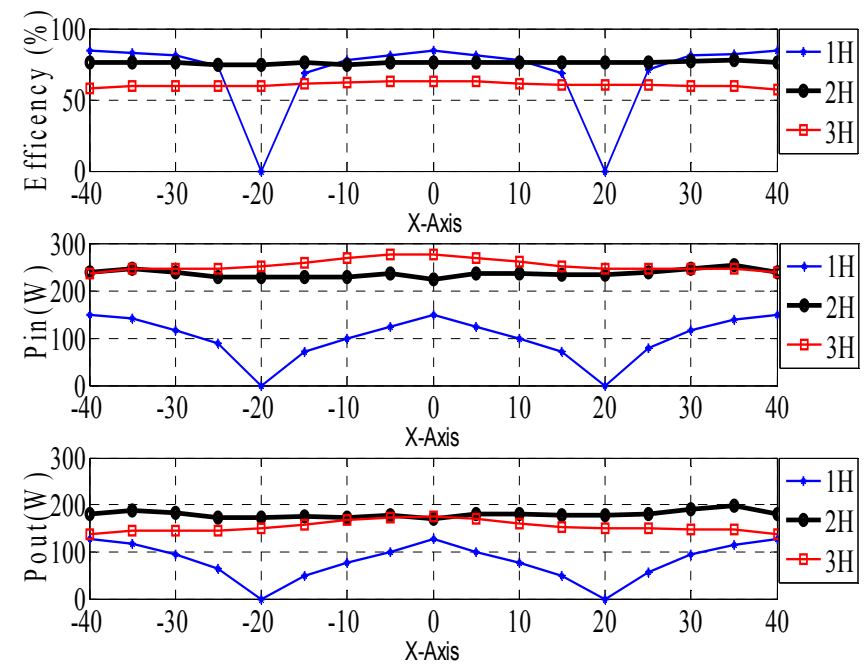

(a)
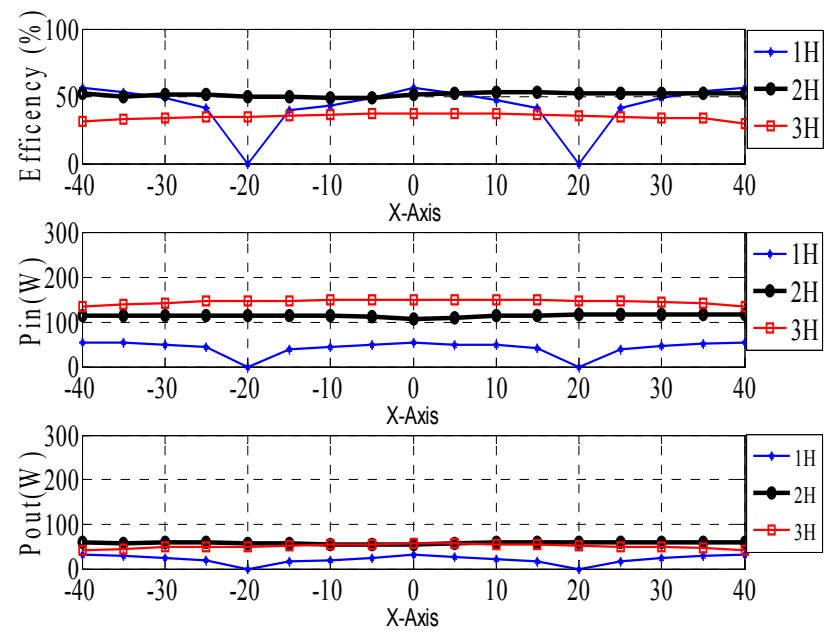

(b)

Figure 8. Efficiency, input power, and output power of the IPT system in motion. (a) Air gap: $10 \mathrm{~mm}$ (b) Air gap: $20 \mathrm{~mm}$.

Table 6. Motion effect of the IPT system as moving along X-axis; mode $1 \mathrm{H}$ (fsw: $20 \mathrm{kHz}$ ).

\begin{tabular}{|c|c|c|c|c|c|c|c|c|c|c|}
\hline Air Gap & $X$-Axis (mm) & -40 & -30 & -20 & -10 & 0 & 10 & 20 & 30 & 40 \\
\hline \multirow{3}{*}{ Air Gap: $10 \mathrm{~mm}$} & Efficiency & $85 \%$ & $81 \%$ & $0 \%$ & $78 \%$ & $85 \%$ & $78 \%$ & $0 \%$ & $81 \%$ & $85 \%$ \\
\hline & Input power $(\mathrm{W})$ & 150 & 117 & 0 & 98 & 150 & 98 & 0 & 117 & 150 \\
\hline & Output power (W) & 128 & 95 & 0 & 77 & 128 & 77 & 0 & 95 & 128 \\
\hline \multirow{3}{*}{ Air Gap: $20 \mathrm{~mm}$} & Efficiency & $56 \%$ & $49 \%$ & $0 \%$ & $43 \%$ & $56 \%$ & $43 \%$ & $0 \%$ & $49 \%$ & $56 \%$ \\
\hline & Input power $(\mathrm{W})$ & 54 & 49 & 0 & 45 & 54 & 45 & 0 & 49 & 54 \\
\hline & Output power $(\mathrm{W})$ & 30 & 24 & 0 & 19 & 30 & 19 & 0 & 24 & 30 \\
\hline
\end{tabular}


Table 7. Motion effect of the IPT system as moving along X-axis; mode $2 \mathrm{H}$ (fsw: $20 \mathrm{kHz}$ ).

\begin{tabular}{lllllllllll}
\hline Air Gap & X-Axis (mm) & $-\mathbf{4 0}$ & $-\mathbf{3 0}$ & $-\mathbf{2 0}$ & $\mathbf{- 1 0}$ & $\mathbf{0}$ & $\mathbf{1 0}$ & $\mathbf{2 0}$ & $\mathbf{3 0}$ & $\mathbf{4 0}$ \\
\hline \multirow{3}{*}{ Air Gap: 10 mm } & Efficiency & $76 \%$ & $76 \%$ & $75 \%$ & $75 \%$ & $76 \%$ & $75 \%$ & $75 \%$ & $76 \%$ & $76 \%$ \\
& Input power (W) & 238 & 240 & 230 & 230 & 224 & 230 & 230 & 240 & 238 \\
& Output power (W) & 181 & 182 & 173 & 173 & 169 & 173 & 173 & 182 & 181 \\
\hline \multirow{3}{*}{ Air Gap: 20 mm } & Efficiency & $52 \%$ & $51 \%$ & $50 \%$ & $49 \%$ & $51 \%$ & $49 \%$ & $50 \%$ & $51 \%$ & $52 \%$ \\
& Input power (W) & 115 & 114 & 114 & 113 & 107 & 113 & 114 & 114 & 115 \\
& Output power (W) & 59.4 & 58.3 & 57.2 & 55.1 & 54.1 & 55.1 & 57.2 & 58.3 & 59.4 \\
\hline
\end{tabular}

Table 8. Motion effect of the IPT system as moving along X-axis; mode $3 \mathrm{H}$ (fsw: $20 \mathrm{kHz}$ ).

\begin{tabular}{lllllllllll}
\hline Air Gap & X-Axis (mm) & -40 & $-\mathbf{3 0}$ & $\mathbf{- 2 0}$ & $\mathbf{- 1 0}$ & $\mathbf{0}$ & $\mathbf{1 0}$ & $\mathbf{2 0}$ & $\mathbf{3 0}$ & $\mathbf{4 0}$ \\
\hline \multirow{3}{*}{ Air Gap: 10 mm } & Efficiency & $58.1 \%$ & $59.4 \%$ & $59.7 \%$ & $62.4 \%$ & $63.0 \%$ & $62.4 \%$ & $59.7 \%$ & $59.4 \%$ & $58.1 \%$ \\
& Input power (W) & 237 & 246 & 250.5 & 268.5 & 277.5 & 268.5 & 250.5 & 246 & 237 \\
& Output power (W) & 137.8 & 146.2 & 149.6 & 167.4 & 174.8 & 167.4 & 149.6 & 146.2 & 137.8 \\
\hline \multirow{3}{*}{ Air Gap: 20 mm } & Efficiency & $31.3 \%$ & $33.7 \%$ & $34.4 \%$ & $36.1 \%$ & $37.5 \%$ & $36.1 \%$ & $34.4 \%$ & $33.7 \%$ & $31.3 \%$ \\
& Input power (W) & 135 & 142.5 & 145.5 & 150 & 150 & 150 & 145.5 & 142.5 & 135 \\
& Output power (W) & 42.3 & 48.0 & 50.0 & 54.1 & 56.2 & 54.1 & 50.0 & 48.0 & 42.3 \\
\hline
\end{tabular}

Figure 9 shows the waveforms of the P topology IPT system operated at mode $1 \mathrm{H}$. As shown in Figure $4 \mathrm{~b}$, the $\mathrm{X}-\mathrm{Z}$ table is utilized to move the secondary E-shaped core along the $X$-axis at a speed of $16.7 \mathrm{~cm} / \mathrm{s}$. The time intervals of $\mathrm{T} 1, \mathrm{~T} 2$, and $\mathrm{T} 3$ are $0.24 \mathrm{~s}$. The mode $1 \mathrm{H}$ is designed as one H-bridge inverter operated at each time interval. Therefore, voltage $\left(\mathrm{v}_{\mathrm{s}}\right)$ and current $\left(\mathrm{i}_{\mathrm{s}}\right)$ waveforms of the IPT system are varied seriously.

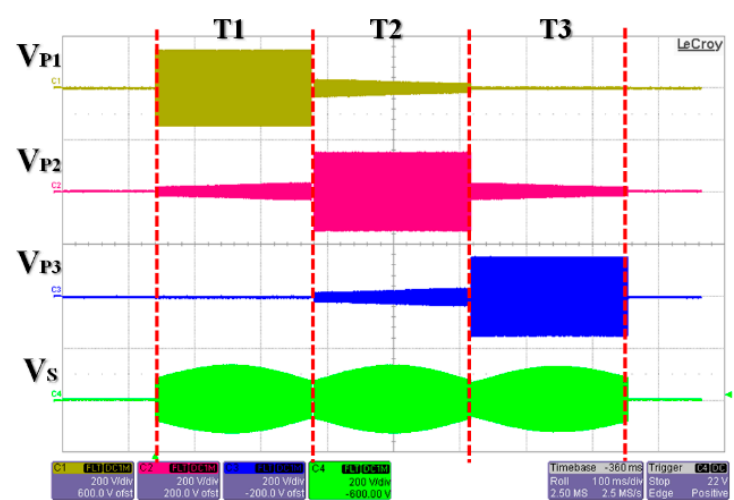

(a)

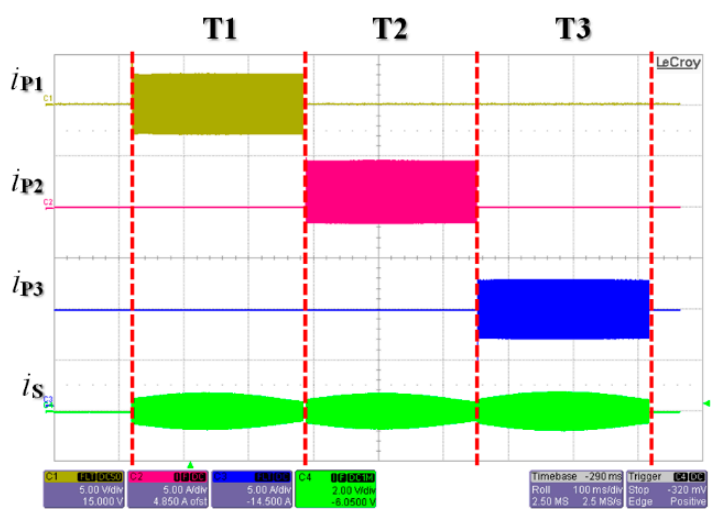

(b)

Figure 9. Waveforms of the P topology IPT system operated at mode $1 \mathrm{H}$ (air gap: $10 \mathrm{~mm}$; time: 100 ms /div.; voltage: $200 \mathrm{v} /$ div.; current $\mathrm{i}_{\mathrm{p} 1}, \mathrm{i}_{\mathrm{p} 2}$, and $\mathrm{i}_{\mathrm{p} 3}: 5 \mathrm{~A} /$ div.; current $\mathrm{i}_{\mathrm{s}}: 2 \mathrm{~A} /$ div.). (a) Voltages; (b) Currents.

Figure 10 shows the waveforms of the $\mathrm{P}$ topology IPT system operated at mode $2 \mathrm{H}$ (speed: $16.7 \mathrm{~cm} / \mathrm{s})$. The time intervals of $\mathrm{T} 1, \mathrm{~T} 2, \mathrm{~T} 3$, and $\mathrm{T} 4$ are $0.24 \mathrm{~s}$. The voltage $\left(\mathrm{v}_{\mathrm{s}}\right)$ and current $\left(\mathrm{i}_{\mathrm{s}}\right)$ waveforms of mode $2 \mathrm{H}$ are high and stable due to the adequate overlap operation for three $\mathrm{H}$-bridge inverters. Compared Figure 10 (mode $2 \mathrm{H}$ ) with Figure 9 (mode $1 \mathrm{H}$ ), mode $2 \mathrm{H}$ exhibits high efficiency $76 \%$, stable input power and output power. Therefore, the $\mathrm{P}$ topology IPT system operated at mode $2 \mathrm{H}$ is validated to meet the requirements for bus-stop-powered EVs. 


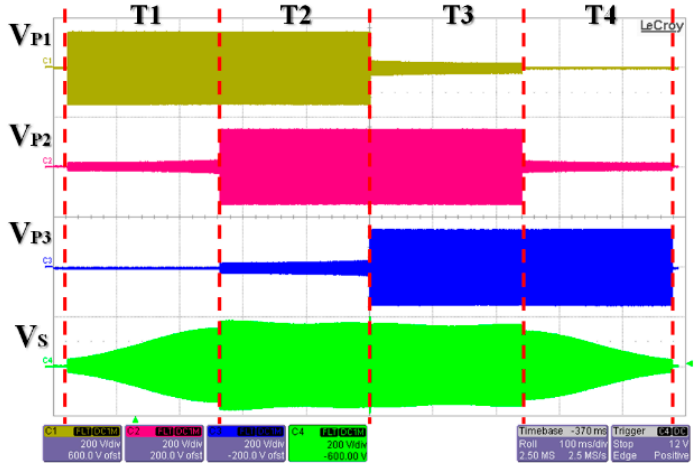

(a)

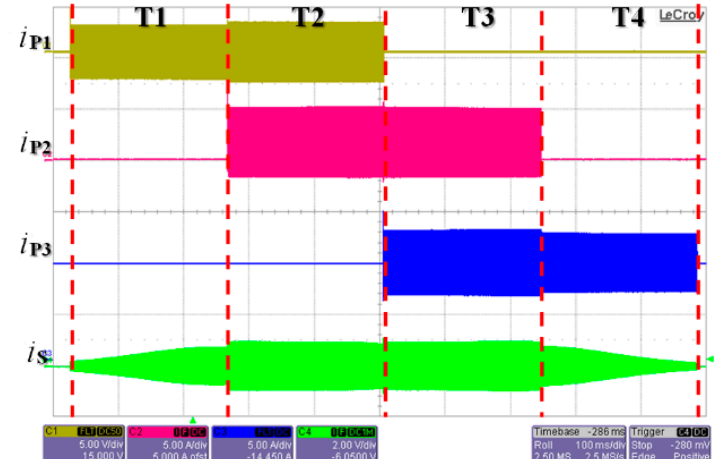

(b)

Figure 10. Waveforms of the $\mathrm{P}$ topology IPT system operated at mode $2 \mathrm{H}$ (air gap: $10 \mathrm{~mm}$; time: 100 ms/div.; voltage: $200 \mathrm{v} /$ div.; current $\mathrm{i}_{\mathrm{p} 1}, \mathrm{i}_{\mathrm{p} 2}$, and $\mathrm{i}_{\mathrm{p} 3}: 5 \mathrm{~A} /$ div.; current $\mathrm{i}_{\mathrm{s}}: 2 \mathrm{~A} /$ div.) (a) Voltages; (b) Currents.

\section{IPT System Operated at Large Air Gap}

The IPT system operated at large air gap is restricted by the EE-shaped ferrite cores used. Therefore, finite element analysis (FEA) software is utilized to validate the performances of the proposed scheme. Figure 11 shows the IPT system based on the FEA software. According to Figure $2 b$, and Figure 11a which shows the 3D model of the EE-shaped ferrite cores, the dimensions are A (760 mm), B (30 mm), C (760 mm), D (20 mm), E (720 mm), F (40 mm), G (F/2), H (E/2-F/2), and I (A/4-E/4). The air gap between the EE-shaped cores is $150 \mathrm{~mm}$. The material of the EE-shaped cores is 3C90 made by Ferroxcube. Figure 11b shows the circuit of the SP topology based on the FEA software. The primary and secondary excitation windings are 11 turns and 11 turns, respectively. The primary and secondary inductances are $L_{p}(147 \mu \mathrm{H})$ and $L_{S}(147 \mu \mathrm{H})$. The primary series capacitor and secondary parallel capacitor are $C_{p}(0.43 \mu \mathrm{F})$ and $C_{s}(0.43 \mu \mathrm{F})$. Therefore, the resonant frequency is designed as $20 \mathrm{kHz}$.

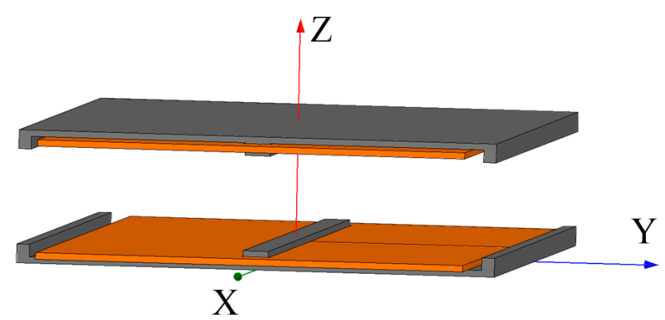

(a)

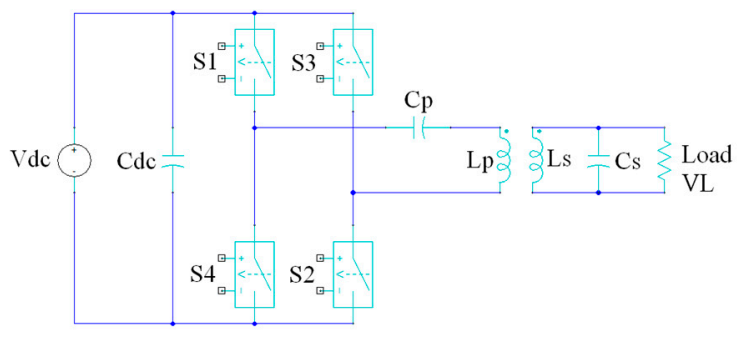

(b)

Figure 11. IPT system based on finite element analysis ( $\mathrm{V}_{\mathrm{dc}}: 300 \mathrm{~V}$; fsw: $20 \mathrm{kHz}$; air gap: $150 \mathrm{~mm}$ ). (a) 3D Model of EE-shaped ferrite cores; (b) Circuit of the SP topology.

Figure 12a,b show the waveforms of the SP topology IPT system based on FEA. As shown in Figure 12a, the input voltage is a square wave with amplitude $300 \mathrm{~V}$ and the output voltage is a sinusoidal wave with amplitude $793 \mathrm{~V}$. The amplitudes of the input current and output current are $41 \mathrm{~A}$ and $43 \mathrm{~A}$ as shown in Figure 12b. The efficiency, input power, and output power of the SP topology IPT system are $80 \%, 3930 \mathrm{~W}$, and $3136 \mathrm{~W}$, respectively.

Figure 12c,d show the waveforms of the P topology IPT system based on FEA. As shown in Figure 12c, the input voltage is a square wave with amplitude $300 \mathrm{~V}$ and the output voltage is a sinusoidal wave with amplitude $432 \mathrm{~V}$. The amplitudes of the input current and output current are 25.5 A and $23 \mathrm{~A}$ as shown in Figure 12d. The efficiency, input power, and output power of the 
P topology IPT system are 59.8\%, $1560 \mathrm{~W}$, and $934 \mathrm{~W}$, respectively. Comparing the SP topology (Figure 12a,b) with the P topology (Figure 12c,d), the IPT system adopting a SP topology exhibits superior performances under large $(150 \mathrm{~mm})$ air gap conditions.

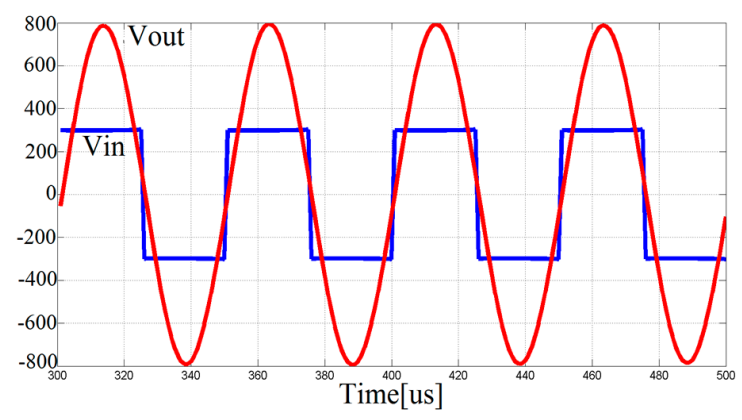

(a)

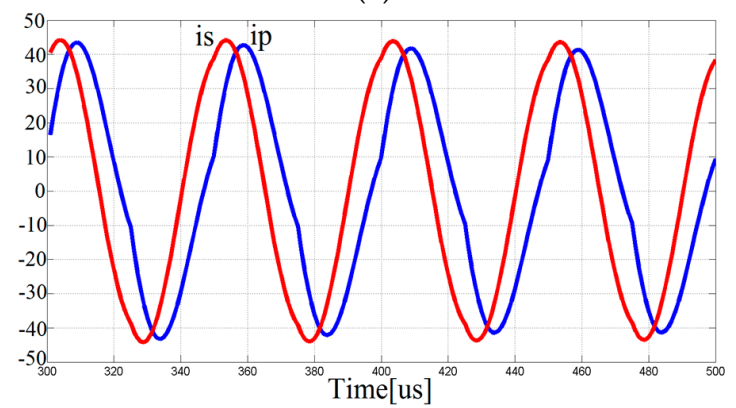

(b)

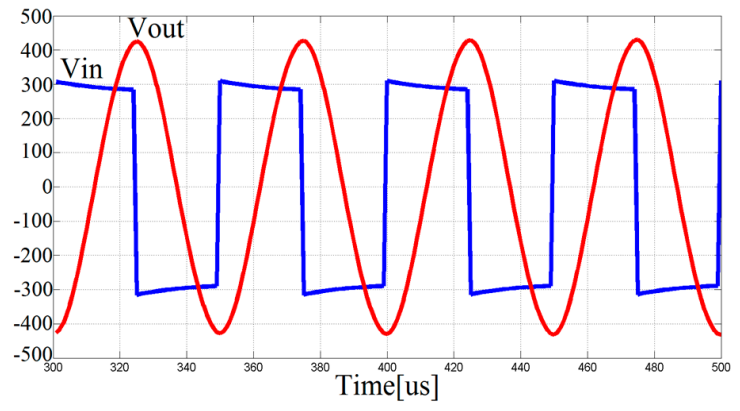

(c)

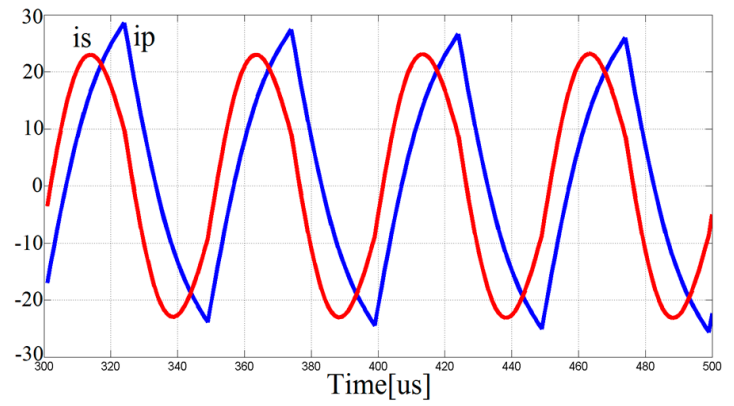

(d)

Figure 12. Waveforms of the IPT system based on finite element analysis $\left(\mathrm{V}_{\mathrm{dc}}: 300 \mathrm{~V}\right.$; fsw: $20 \mathrm{kHz}$; air gap: $150 \mathrm{~mm}$ ). (a) Input and output voltages of SP topology; (b) Input and output currents of SP topology; (c) Input and output voltages of P topology; (d) Input and output currents of P topology.

\section{Conclusions}

This study discusses the IPT system based on EE-shaped ferrite cores. The transfer function and frequency response of the SP topology and P topology IPT systems are presented. The SP topology 
is suitable for large air gaps and the P topology is suitable for small air gaps. The issues of the IPT system such as efficiency, air gap, displacement, dislocation, and motion are discussed. Finite element analysis is utilized to validate the SP topology IPT system operated under large air gap conditions. Furthermore, multi-H-bridge inverters are utilized to increase the transfer power of the IPT system. The three operation modes $(1 \mathrm{H}, 2 \mathrm{H}$, and $3 \mathrm{H})$ of three $\mathrm{H}$-bridge inverters are controlled by position regulation sensors. Among mode $1 \mathrm{H}, 2 \mathrm{H}$, and $3 \mathrm{H}$, mode $2 \mathrm{H}$ exhibits superior performance in the IPT system and meets the requirements for bus-stop-powered EVs.

Acknowledgments: This work was supported by the Ministry of Science and Technology of R.O.C. under grant MOST 103-2221-E-216-008.

Author Contributions: Chung-Chuan Hou modeled the system, analyzed the experimental data, wrote the draft and revised the paper; Kuei-Yuan Chang established the experimental platform, measured and analyzed the experimental data.

Conflicts of Interest: The authors declare no conflict of interest.

\section{References}

1. Miller, J.M.; Onar, O.C.; Chinthavali, M. Primary-side power flow control of wireless power transfer for electric vehicle charging. IEEE J. Emerg. Sel. Top. Power Electron. 2015, 3, 147-162. [CrossRef]

2. Wang, C.; Stielau, O.H.; Covic, G.A. Design considerations for a contactless electric vehicle battery charger. IEEE Trans. Ind. Electron. 2005, 52, 1308-1314. [CrossRef]

3. Li, S.; Mi, C.C. Wireless power transfer for electric vehicle applications. IEEE J. Emerg. Sel. Top. Power Electron. 2015, 3, 4-17.

4. Choi, S.Y.; Gu, B.W.; Jeong, S.Y.; Rim, C.T. Advances in wireless power transfer systems for roadway-powered electric vehicles. IEEE J. Emerg. Sel. Top. Power Electron. 2015, 3, 18-36. [CrossRef]

5. Zhang, W.; Wong, S.; Tse, C.K.; Chen, Q. An optimized track length in roadway inductive power transfer systems. IEEE J. Emerg. Sel. Top. Power Electron. 2014, 2, 598-608. [CrossRef]

6. Shin, J.; Shin, S.; Kim, Y.; Ahn, S.; Lee, S.; Jung, G.; Jeon, S.; Cho, D. Design and implementation of shaped magnetic-resonance-based wireless power transfer system for roadway-powered moving electric vehicles. IEEE Trans. Ind. Electron. 2014, 61, 1179-1192. [CrossRef]

7. Chen, L.; Nagendra, G.R.; Boys, J.T.; Covic, G.A. Double-coupled systems for IPT roadway applications. IEEE J. Emerg. Sel. Top. Power Electron. 2015, 3, 37-49. [CrossRef]

8. Nagendra, G.R.; Chen, L.; Covic, G.A.; Boys, J.T. Detection of EVs on IPT highways. IEEE J. Emerg. Sel. Top. Power Electron. 2014, 2, 584-597. [CrossRef]

9. Kurs, A.; Karalis, A.; Moffatt, R.; Joannopoulos, J.D.; Fisher, P.; Soljacic, M. Wireless power transfer via strongly coupled magnetic resonances. Science 2007, 317, 83-86. [CrossRef] [PubMed]

10. Zhang, W.; Wong, S.; Tse, C.K.; Chen, Q. Analysis and comparison of secondary series- and parallel-compensated inductive power transfer systems operating for optimal efficiency and load-independent voltage-transfer ratio. IEEE Trans. Power Electron. 2014, 29, 2979-2990. [CrossRef]

11. Aldhaher, S.; Luk, P.C.; Whidborne, J.F. Electronic tuning of misaligned coils in wireless power transfer systems. IEEE Trans. Power Electron. 2014, 29, 5975-5982. [CrossRef]

12. Pantic, Z.; Lee, K.; Lukic, S.M. Multifrequency inductive power transfer. IEEE Trans. Power Electron. 2014, 29, 5995-6005. [CrossRef]

13. Pinuela, M.; Yates, D.C.; Lucyszyn, S.; Mitcheson, P.D. Maximizing dc-to-load efficiency for inductive power transfer. IEEE Trans. Power Electron. 2013, 28, 2437-2447. [CrossRef]

14. Musavi, F.; Eberle, W. Overview of wireless power transfer technologies for electric vehicle battery charging. IET Power Electron. 2013, 7, 60-66. [CrossRef] 